\title{
Study of Functional Outcome of Anterior Cervical Decompression and Fusion Using Tricortical Iliac Bone Graft for Degenerative Cervical Spondylotic Myelopathy with Modified Japanese Orthopedic Association Score
}

\author{
Ayush Sharma ${ }^{1 *}$, Mayur Dhake ${ }^{1}$, Vijay Singh ${ }^{1}$, Natraj B ${ }^{1}$, Rajat Mahajan ${ }^{2}$, Prashant Kamble ${ }^{3}$, Pritish Khardikar ${ }^{1}$, Tarun Chabra ${ }^{4}$, Akshay \\ Jadhav' ${ }^{1}$ and Darshan Devani ${ }^{1}$ \\ ${ }^{1}$ Department of Orthopedic and Spine Surgeries, Dr BR Ambedker Central Railway Hospital, Mumbai, India \\ ${ }^{2}$ Indian Spinal Injuries Center, New Delhi, India \\ ${ }^{3}$ King Edward Memorial Hospital and Seth G S Medical Collage, Mumbai, India \\ ${ }^{4}$ Ganga Hospital, Coimbatore, India
}

\begin{abstract}
Objective: To determine functional outcome of anterior cervical decompression and fusion using tricortical iliac bone graft (ACDF) for degenerative cervical spondylotic myelopathy with modified Japanese orthopedic association score (MJOA).

Materials and Methods: 60 diagnosed cases of one and two levels cervical myelopathy were prospectively analyzed preoperatively and at 3 months, 6 months, 1 year using MJOA.

Results: 46 patients underwent Single level ACDF with C5-C6 the commonest level to be affected. The correlation between Duration of Symptoms to Preoperative and postoperative MJOA was statistically significant. We noted statistically significant improvement in symptoms of axial neck pain, radicular arm pain, clumsy hand, and gait disturbances post operatively at one year. Statically significant difference was noted while comparison MJOA of Preoperative to 6 months and 1 year, and 3 months to 6 months and 1 year. Statistically significant difference in blood loss and anesthesia time for one level fusion compared with two level fusions was also noted. The fusion rate for single level ACDF was $95.65 \%$ compared to $71.42 \%$ for two levels.

Conclusion: Functional outcomes in operated patients at 1-year follow up are better if ACDF surgery is done early. Symptoms of axial neck pain; radicular arm pain, clumsy hand and gait disturbances show significant improvement at one year follow up. While bladder and bowel involvement showed the least recovery. Significant improvement in function occurs postoperatively between 3 and 6 months, and then it plateaus from 6 months to 1 year. Fusion rates for single level ACDF are better than two levels ACDF.
\end{abstract}

Keywords: Cervical myelopathy; Cervical fusion; ACDF; Modified japanese orthopedic association score

\section{Introduction}

Cervical spondylotic myelopathy refers to clinical syndromes arising from a combination of static and dynamic compression of neural structures due to disc herniation, osteophyte formation, hypertrophy of facet joints and hypertrophy of ligaments, as well as due to vascular phenomenon. Surgical intervention is considered if conservative treatment fails. The surgical aim is to decompress, stabilize and to restore the alignment of spine. LaRocca [1] was one of the first to recommended early spinal cord decompression with or without stabilization to halt the progression of the disease for patients presenting with moderate functional disability. The management of cervical spondylotic myelopathy continues to be shrouded in controversy. Common surgical technique includes discectomy without fusion or discectomy with fusion (ACDF) [2-8] and corpectomy with fusion (ACCF) $[3,5,9,10]$. Fusion technique includes use of bone graft or cage and addition of plate $[9,10]$. ACDF has been confirmed to be beneficial in treatment of cervical myelopathy in both long and short-term follow up $[11,12]$. In a meta-analysis of ACDF vs. ACCF for treatment of cervical myelopathy in 2015 authors concluded that blood loss and numbers of complications during surgery in ACDF were significantly less than that with ACCF, while the clinical outcome was similar for both the procedures [13]. In the present study, we have analyzed post-operative functional recovery in patients undergoing anterior cervical decompression and fusion surgery for degenerative cervical spondylotic myelopathy according to 'Modified Japanese Orthopaedic Association Scores' (MJOA).

\section{Materials and Methods}

60 patients between August 2009 to March 2014 with clinical and radiological diagnosis of cervical spondylotic myelopathy of one or two levels were prospectively analyzed using 'Modified Japanese Orthopedic Association scoring' (MJOA). All cases were operated using anterior approach under fluoroscopic guidance. Following discectomy, autologous tricortical iliac bone graft was used for fusion. MJOA scoring was done pre-operatively and post-operatively at 3 months, 6 months and at 1 year (Table 1). Data was collected by direct observations as per the performa prepared. Radiographs of the cervical spine (Antero

${ }^{*}$ Corresponding author: Ayush Sharma, Department of Orthopedic and Spine Surgeries Dr BR Ambedker Central Railway Hospital, Byculla East, Mumbai, India, Tel: +919004549623, E-mail: drayush@gmail.com

Received August 13, 2015; Accepted September 05, 2015; Published September 07, 2015

Citation: Sharma A, Dhake M, Singh V, Natraj B, Mahajan R, et al. (2015) Study of Functional Outcome of Anterior Cervical Decompression and Fusion Using Tricortical Iliac Bone Graft for Degenerative Cervical Spondylotic Myelopathy with Modified Japanese Orthopedic Association Score. J Spine 4: 255.doi:10.4172/21657939.1000255

Copyright: ( 2015 Sharma A, et al. This is an open-access article distributed under the terms of the Creative Commons Attribution License, which permits unrestricted use, distribution, and reproduction in any medium, provided the original author and source are credited. 
Citation: Sharma A, Dhake M, Singh V, Natraj B, Mahajan R, et al. (2015) Study of Functional Outcome of Anterior Cervical Decompression and Fusion Using Tricortical Iliac Bone Graft for Degenerative Cervical Spondylotic Myelopathy with Modified Japanese Orthopedic Association Score. J Spine 4: 255.doi:10.4172/2165-7939.1000255

Page 2 of 4

\begin{tabular}{|c|c|}
\hline According to modified Japanese orthopedics association scoring \\
\hline Mild & -14 and above \\
\hline Moderate & $-10-13$. \\
\hline Severe & -9 and below \\
\hline
\end{tabular}

Table 1: Modified Japanese orthopedics association scoring.

posterior and Lateral) and MRI of the spine was done in all cases. Data was analyzed using - McNemar Test: For comparison between preoperative and post-operative symptoms at 1 year follow up of axial neck pain, radicular arm pain, clumsy hands, gait disturbances and bowel and bladder symptom. ( $\mathrm{p}=0.05$ is considered to be significant). KruskalWallis One Way Analysis of Variance on Ranks and All Pairwise Multiple Comparison Procedures (Turkey Test): For comparison of MJOA score at various time intervals among the cases. Spearman rank correlation coefficient: -For correlation between Duration of symptoms till surgery and Pre-operative MJOA Correlation between Duration of symptoms till surgery and Post-operative MJOA at 1 year, Chi-Square tests (Pearson Chi-Square, Continuity Correction, Fisher's Exact Test): -For association among the cases between- Number of levels MannWhitney test: - For comparison of blood loss and Anesthesia time by number of levels.

\section{Results}

The mean age in our study was 51.07 years with $( \pm 9.39$ SD) range 30 years to 72 years. Out of 60 patients enrolled 36 patients were male and 24 were female. Out of 60 patients, 22 patients presented with signs and symptoms of myelopathy alone while remaining 38 patients had signs and symptoms of myelopathy and radiculopathy. At presentation, 34 patients had mild disability (i.e. MJOA 14 and above), 12 patients had moderate disability (i.e. MJOA 10 to 13), 14 patients had severe disability (i.e. MJOA 9 and below). At one year follow up, 42 patients had mild disability (i.e. MJOA 14 and above), 2 patients had moderate disability (i.e. MJOA 10 to 13 ) and 16 patients had severe disability (i.e. MJOA 9 and below) (Figure 1). 46 patients underwent single level ACDF with C5-C6 being the commonest level to be affected in 24 patients. In 14 patients, two level ACDF was done (Figure 2). In our study, the mean duration of symptoms present before surgical treatment was 3.63 months $( \pm 2.57 \mathrm{SD})$. The correlation between duration of symptoms (months) to pre-operative MJOA scores was statistically significant ( $p$-value $=0.015$ ). The correlation between duration of symptoms (months) to post-operative MJOA scores was statistically significant. ( $\mathrm{p}$-value $=0.013$ ) (Table 2$)$. We noted statistically significant improvement in symptoms of axial neck pain ( $\mathrm{p}$ value $=0.00012)$, radicular arm pain $(\mathrm{p}$ value $=0.004)$, clumsy hand $(\mathrm{p}$ value $=0.031$ ), gait disturbances $(p$ value $=0.039)$, post-operatively at 1

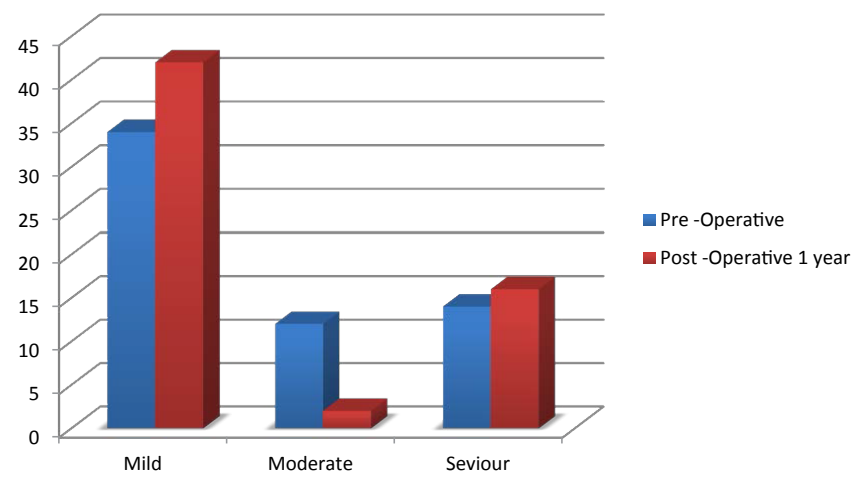

Figure 1: Disability grade as measured by the mJOA score. year follow up. All Pairwise Multiple Comparison Procedures (Turkey test) applied, there was statistically significant difference noted with comparison pairs of pre-operative vs. 6 months, pre-operative vs. 1 year, 3 months vs. 6 months, 3 months vs. 1 year. But no significant difference was found between pre-operative MJOA vs. post-operative 3 months score and post-operative 6 months MJOA vs. post-operative MJOA at 1 year (Table 3). This suggests that there was no significant improvement immediately after surgery to 3 months. But the functional recovery increased in post-operative period from 3 months to 6 months with plateaued phase from 6 months to 1 year (Figure 3). Also with Mann-Whitney test, we noted a statistically significant difference when blood loss and anesthesia time for one level fusion compared with two level fusions. In our series for single level fusion, mean blood loss was $114.78 \mathrm{ml}( \pm 18.6 \mathrm{~S} \mathrm{D})$ and anesthesia time 104.78 minutes $( \pm 12.01 \mathrm{SD})$. For two level fusions, mean blood loss was $250 \mathrm{ml}( \pm 40.83 \mathrm{SD})$ and anesthesia time 172.86 minutes (Figure 4).

Out of 60 patients, 46 patients underwent single level noninstrumented ACDF. Only 2 (4.34\%) had psuedoarthrosis (Figure 5). The fusion rate for single level ACDF in our series was $95.65 \%$ (Figure 6). Remaining 14 patients underwent two level non-instrumented ACDF out of which 4 patients (28.57\%) had pseudoarthrosis. The fusion rate for two levels ACDF in our series is $71.42 \%$ (Figure 7). Overall

\section{Levals Affected}

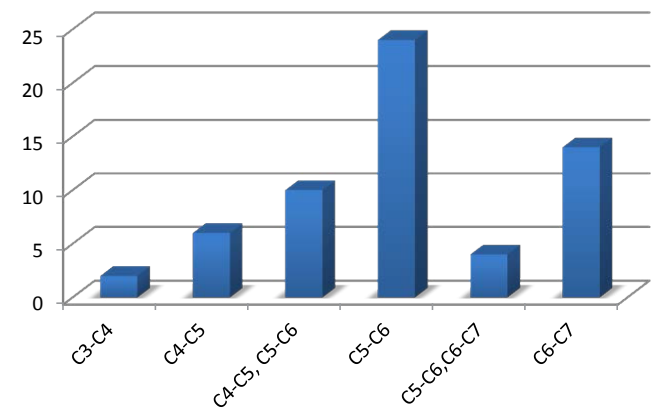

Levals Affected

Figure 2: Distribution among the cases of-levels affected.

\begin{tabular}{|l|c|c|c|c|c|c|}
\hline Variables & Mean & SD & Median & IQR & & \\
\cline { 1 - 5 } Preop MJOA & 12.40 & 3.68 & 14.00 & 5.25 & 56.754 & $2.90 \mathrm{E}-12$ \\
\hline Postop MJOA at 3 months & 12.33 & 4.02 & 14.00 & 6.50 & \multirow{2}{*}{$\begin{array}{c}\text { Difference is } \\
\text { significant }\end{array}$} \\
\hline Postop MJOA at 6 months & 14.17 & 4.32 & 16.50 & 6.25 & \\
\hline Postop MJOA at 1 year & 14.27 & 4.59 & 17.00 & 7.50 & \\
\hline
\end{tabular}

Table 2: Comparison of MJOA score at various time intervals.

\begin{tabular}{|l|c|c|c|c|}
\hline Comparison pairs & $\begin{array}{c}\text { Difference of } \\
\text { Ranks }\end{array}$ & Q-value & p-value & Difference is- \\
\hline Pre-op vs. 3 months & 2.000 & 0.283 & $>0.05$ & Not significant \\
\hline Pre-op vs. 6 months & 48.000 & 6.788 & $\leq 0.05$ & Significant \\
\hline Pre-op vs. 1 year & 50.000 & 7.071 & $\leq 0.05$ & Significant \\
\hline 3 months vs. 6 months & 46.000 & 6.505 & $\leq 0.05$ & Significant \\
\hline 3 months vs. 1 year & 48.000 & 6.788 & $\leq 0.05$ & Significant \\
\hline 6 months vs. 1 year & 2.000 & 0.283 & $>0.05$ & Not significant \\
\hline
\end{tabular}

${ }^{*}$ The mean difference is significant at the 0.05 levels.

Comparison of MJOA score at various time intervals among the cases was done using all Pairwise Multiple Comparison Procedures (Turkey Test). There was statistically significant difference noted with comparison pairs of pre-operative vs. 6 months, pre-operative vs. 1 year, 3 months vs. 6 months, 3 months vs. 1 year Table 3: All pairwise multiple comparison procedures (Turkey Test). 
Citation: Sharma A, Dhake M, Singh V, Natraj B, Mahajan R, et al. (2015) Study of Functional Outcome of Anterior Cervical Decompression and Fusion Using Tricortical Iliac Bone Graft for Degenerative Cervical Spondylotic Myelopathy with Modified Japanese Orthopedic Association Score. J Spine 4: 255.doi:10.4172/2165-7939.1000255

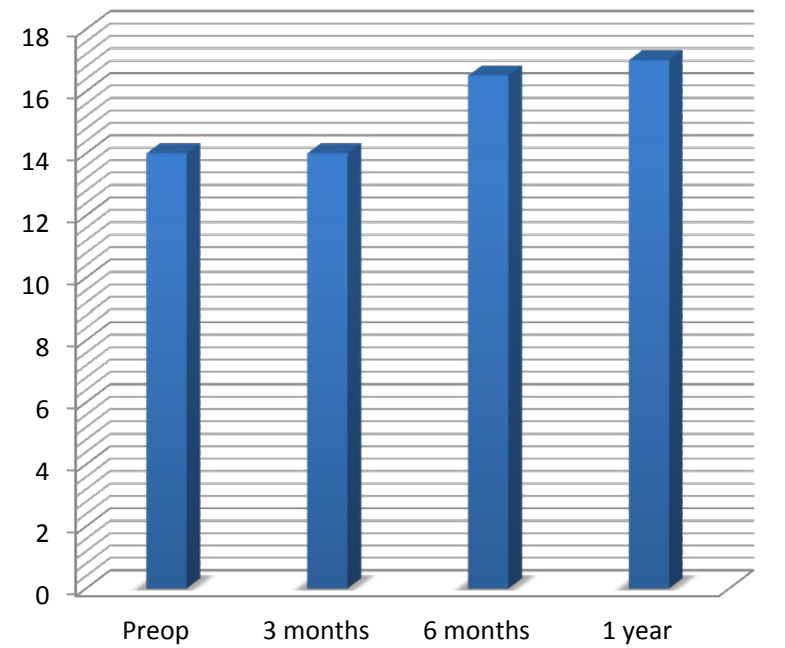

\section{Comparisons of MJOA median score at various time interval}

Figure 3: Comparison of MJOA score at various time intervals among the cases.

Blood loss \& anaesthesia time by number of levels

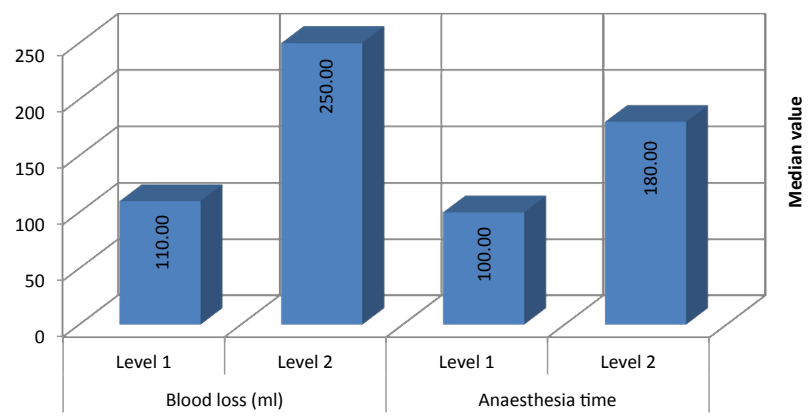

GRAPH NO. 4

Figure 4: Blood loss and anesthesia time by number of levels.

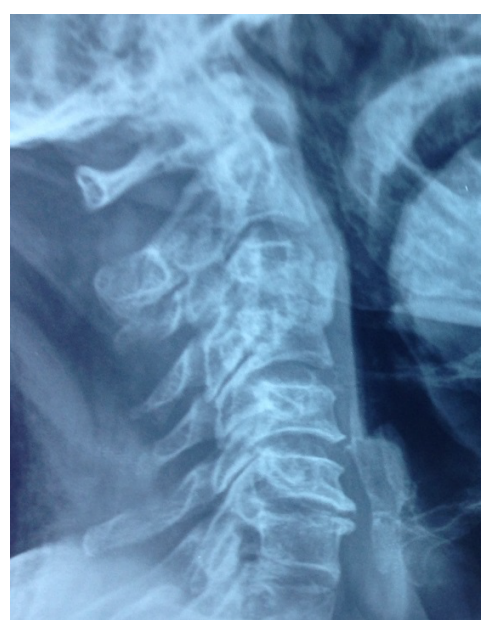

Figure 5: $X$ ray showing pseudoarthrosis in a case of $\mathrm{C} 3-\mathrm{C} 4$, spondylotic myelopathy treated by ACDF with tricortical iliac bone graft at 1 year follow up.

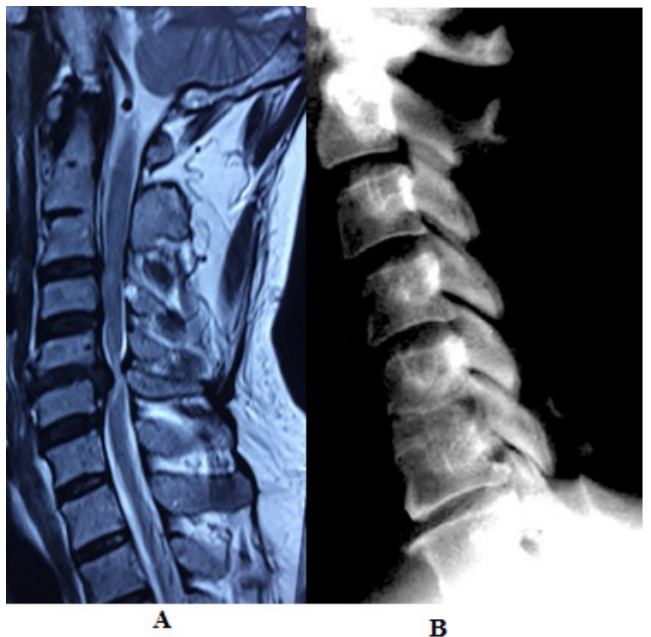

Figure 6: MRI showing C4-C5, spondylotic myelopathy (A) C4-C5, fusion after ACDF with tricortical iliac bone graft at 1 year follow up (B).

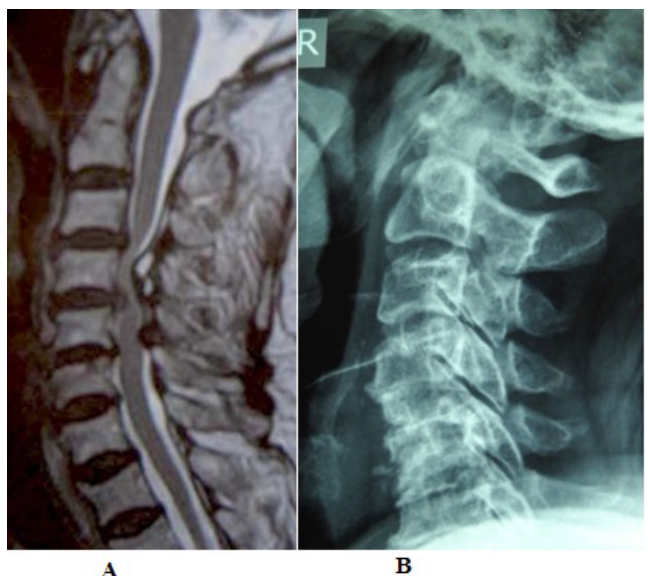

Figure 7: MRI showing C4-C5, C5-C6 spondylotic myelopathy (A) C4-C5, C5C6 fusion after ACDF with tricortical iliac bone graft at 1 year follow up (B).

fusion rate in 60 patients was $90 \%$. In our study out of 60 patients, 20 patients had bowel/bladder symptoms pre-operatively out of which 6 patients (30\%) had complete relief post-operatively at 1 year followup while 14 patients $(70 \%)$ had persistent bowel/bladder symptoms post-operatively at 1 year follow up. Also 2 patient who did not have any pre-operative bowel/bladder symptoms developed bowel/bladder symptoms in post-operative period.

\section{Discussion}

The management of cervical spondylotic myelopathy continues to be debated due to the inadequacy of information available about natural history of this disorder [14,15]. However there is some agreement in literature that a shorter duration of symptoms and milder neurological deficit prior to surgery yields a better post-surgical outcome. Successful surgical treatment of cervical spondylotic myelopathy rests on identifying the specific pathology responsible for clinical syndrome. The surgical approach is then tailored to deal with various static and dynamic factors causing the spinal cord compression, which are often superimposed on congenitally or developmentally narrow spinal canal The location of the compressive pathology, the number of levels 
Citation: Sharma A, Dhake M, Singh V, Natraj B, Mahajan R, et al. (2015) Study of Functional Outcome of Anterior Cervical Decompression and Fusion Using Tricortical Iliac Bone Graft for Degenerative Cervical Spondylotic Myelopathy with Modified Japanese Orthopedic Association Score. J Spine 4: 255.doi:10.4172/2165-7939.1000255

Page 4 of 4

involved, the sagittal cervical spine alignment and the presence or absence of instability and axial neck pain, helps in the decision making as to which approach would be most appropriate for a particular patient. In our study, 60 patients of cervical spondylotic myelopathy were treated by anterior cervical decompression and fusion using tricortical iliac bone graft. Majority (63.3\%) of patients presented with symptoms of myelopathy and radiculopathy. C5-C6 levels were most commonly involved in 40\% followed by C6-C7 in 23.3\%. Multiple level involvements were seen in $23.5 \%$ of cases. Chagas in his article reported C5 to be the most frequently involved vertebral body in spondylotic myelopathy [16]. Mean duration of time between start of symptom and surgery was 3.63 months. The correlation between Duration of Symptoms to preoperative and post-opeative MJOA scores was statistically significant. Ebersold in his study of 100 cases concluded the only factor related to potential deterioration was the duration of symptoms pre-operatively. Age, severity of disease, number of levels operated, and pre-operative grade were not predictive of outcome [17]. We noted statistically significant improvement in symptoms of axial neck pain; radicular arm pain, clumsy hand and gait disturbances at 6 months and 1 year follow up. While no significant difference in symptoms were noted at 3 months follow up. Similarly no significant difference was observed between post-operative 6 months MJOA vs. MJOA at 1 year. This suggests that the functional recovery increased significantly in post-operative period from 3 months to 6 months with plateaued phase from 6 months to 1 year. In our series for single level fusion, mean blood loss was 114.78 $\mathrm{ml}$ and anesthesia time 104.78 minutes. For two level fusions, mean blood loss was $250 \mathrm{ml}$ and anesthesia time 172.86 minutes. We noted a statistically significant difference when blood loss and anesthesia time for one level fusion compared with two level fusions. The fusion rate for single level ACDF in our series was $95.65 \%$. The fusion rate for two levels $\mathrm{ACDF}$ in our series is $71.42 \%$. Overall fusion rate in 60 patients was $90 \%$ at one year follow up. Literature search and meta-analysis suggest patients who undergo 2-level ACDF without fixation had lower fusion rates than those who undergo 1-level ACCF without fixation $[18,19]$. In our study, 20 patients had bowel/bladder symptoms pre-operatively out of which only 6 patients (30\%) had completely recovered at 1 year follow-up. Compared to other symptoms bladder and bowel involvement showed the least recovery.

Limitation of Study- Lack of control group to compare the functional result and lack of long term follow up.

\section{Conclusion}

Anterior cervical decompression and fusion with tricortical iliac bone graft surgery is effective in the treatment of cervical spondylotic myelopathy with one and two levels affected. From our study it is evident that Duration of symptoms is related to both pre-operative MJOA and post-operative MJOA scores. We recommend early anterior cervical decompression and fusion as soon as the diagnosis of cervical spondylotic myelopathy is made. Functional outcomes in operated patients at 1-year follow up are better if ACDF surgery is done early. Symptoms of axial neck pain, radicular arm pain, clumsy hand and gait disturbances show significant improvement at one year follow up following surgery compared to bladder and bowel involvement which showed the least recovery. Significant improvement in function occurs post-operatively between 3 and 6 months, and then it plateaus from 6 months to 1 year. Fusion rates for single level ACDF are better than two levels ACDF.

\section{Conflict of Interest}

No funding or grant was taken for the above project.

\section{References}

1. LaRocca H (1988) Cervical spondylotic myelopathy: natural history. Spine (Phila Pa 1976) 13: 854-855.

2. Ding C, Hong Y, Liu H, Shi R, Song Y, et al. (2013) Comparison of cervical disc arthroplasty with anterior cervical discectomy and fusion for the treatment of cervical spondylotic myelopathy. Acta Orthop Belg 79: 338-346.

3. Burkhardt JK, Mannion AF, Marbacher S, Dolp PA, Fekete TF, et al. (2013) A comparative effectiveness study of patient-rated and radiographic outcome after 2 types of decompression with fusion for spondylotic myelopathy: anterior cervical discectomy versus corpectomy. Neurosurg Focus 35: E4.

4. Li J, Zheng Q, Guo X, Zeng X, Zou Z, et al. (2013) Anterior surgical options fo the treatment of cervical spondylotic myelopathy in a long-term follow-up study. Arch Orthop Trauma Surg 133: 745-751.

5. Liu Y, Hou Y, Yang L, Chen H, Wang X, et al. (2012) Comparison of 3 reconstructive techniques in the surgical management of multilevel cervical spondylotic myelopathy. Spine (Phila Pa 1976) 37: E1450-1458.

6. Basu S, Sreeramalingam R (2012) Adjacent level spondylodiscitis after anterior cervical decompression and fusion. Indian J Orthop 46: 360-363.

7. Song KJ, Lee KB, Song JH (2012) Efficacy of multilevel anterior cervical discectomy and fusion versus corpectomy and fusion for multilevel cervical spondylotic myelopathy: a minimum 5 -year follow-up study. Eur Spine J 21 : 1551-1557.

8. Lin Q, Zhou X, Wang X, Cao P, Tsai N, et al. (2012) A comparison of anterior cervical discectomy and corpectomy in patients with multilevel cervical spondylotic myelopathy. Eur Spine J 21: 474-481.

9. Gao R, Yang L, Chen H, Liu Y, Liang L, et al. (2012) Long term results of anterior corpectomy and fusion for cervical spondylotic myelopathy. PLoS One 7: e34811.

10. Burkhardt JK, Mannion AF, Marbacher S, Dolp PA, Fekete TF, et al. (2013) A comparative effectiveness study of patient-rated and radiographic outcome after 2 types of decompression with fusion for spondylotic myelopathy: anterior cervical discectomy versus corpectomy. Neurosurg Focus 35: E4.

11. Liu X, Min S, Zhang H, Zhou Z, Wang H, et al. (2014) Anterior corpectomy versus posterior laminoplasty for multilevel cervical myelopathy: a systematic review and meta-analysis. Eur Spine J 23: 362-372.

12. Yan D, Wang Z, Deng S, Li J, Soo C (2011) Anterior corpectomy and reconstruction with titanium mesh cage and dynamic cervical plate for cervical spondylotic myelopathy in elderly osteoporosis patients. Arch Orthop Trauma Surg 131: 1369-1374.

13. Wen ZQ, Du JY, Ling ZH, Xu HD, Lin XJ (2015) Anterior cervical discectomy and fusion versus anterior cervical corpectomy and fusion in the treatment of multilevel cervical spondylotic myelopathy: systematic review and a metaanalysis. Ther Clin Risk Manag 11: 161-170.

14. Bernard TN Jr, Whitecloud TS 3rd (1987) Cervical spondylotic myelopathy and myeloradiculopathy. Anterior decompression and stabilization with autogenous fibula strut graft. Clin Orthop Relat Res : 149-160.

15. Hukuda S, Mochizuki T, Ogata M, Shichikawa K, Shimomura Y (1985) Operations for cervical spondylotic myelopathy. A comparison of the results of anterior and posterior procedures. J Bone Joint Surg $\mathrm{Br}$ 67: 609-615.

16. Chagas H, Domingues F, Aversa A, Vidal Fonseca AL, de Souza JM (2005) Cervical spondylotic myelopathy: 10 years of prospective outcome analysis of anterior decompression and fusion. Surg Neurol 64 Suppl 1: S1: 30-35.

17. Ebersold MJ, Pare MC, Quast LM (1995) Surgical treatment for cervical spondylitic myelopathy. J Neurosurg 82: 745-751.

18. Mummaneni PV, Kaiser MG, Matz PG, Anderson PA, Groff MW, et al. (2009) Cervical surgical techniques for the treatment of cervical spondylotic myelopathy. J Neurosurg Spine 11: 130-141.

19. Bolesta MJ, Rechtine GR 2nd, Chrin AM (2002) One- and two-level anterior cervical discectomy and fusion: the effect of plate fixation. Spine J 2: 197-203. 